\title{
End-of-Life Care: A Paradigm of Nursing Knowledge
}

\section{José Granero-Molina*}

Department of Nursing and Physical Therapy, Carretera Sacramento S/N, University of Almeria (04120), Spain

Death is the human experience which best exemplifies the limits of science and technology in their fight against nature. In Western societies, family care of the dying becomes substituted by health professionals and institutions which in turn convert death into another productive process of modern economic life [1]. The phenomenon of death, understood more as failure of life rather than a natural limitation of it, has generated not only a technical culture focused on prolonging life but also a practice culture which is a source of knowledge for health sciences. Man does not control death; we know more about it than ever, but still lack the essential knowledge necessary to shed light on its meaning. As such, it is the isolation and solitude of the dying person, together with the taxonomic frenzy marking procedures and behaviors, which characterize the process.

Caring for a dying person involves considering his/her right to information about the illness, therapeutic resources, any alternatives available and the prognosis. This process addresses both standardized and individual experiences [2], a series of circumstances in which nurses, who witness the death, should act as guarantors of the conservation of dignity [3]. The lack of social acknowledgement regarding their role in the patient's comfort, hygiene and satisfaction of basic necessities, together with their absence in the deliberative processes of making moral decisions [4], seems to reduce the relevance of their scientific contribution with regards to end-of-life care [5]. This means ignoring the clinical and care reality, the world of life, of which death is a part (Lebenswelt) [6]. The stages of death lay out by Kübler-Ross, the context of awareness theory of Glaser \& Strauss [7] or Chochinov's conservation of dignity [8], show coping models which emphasize individual characteristics of the dying person and the necessity of skills for his or her care. Patients also characterize nursing competence as technical and practical - knowledge which professional opinion deems non-transferable [9].

The "Illustration program" proves unsuccessful at the stage of death, where instrumentalized reason is useless when facing a subjective, personal or individualized moment. Death calls for us to be involved in the process itself, but it only comes with the experience of the death of another and it is from this that it gets its epistemological value [10]. As opposed to rational knowledge [11], here a more substantial understanding takes priority, of the other and of oneself, which, as professionals and as patients, brings us closer to comprehending the phenomenon. If the responsibility of the physician has always been related to individual health [12], nursing science, with its commitment to practice, should aim to prudently determine (phronesis) suitable actions to be taken depending on the requirements of a particular situation. This requires an art which goes beyond universal theoretical principals; it is a question of using judgment and experience to do the right thing within the sensitive framework of a specific action. Death is a personal and inaccessible event which is experienced and felt; it cannot be defined or calculated. Naturally then, reason cannot be solely be used to explain finitude and as such, when scientific advice is no longer of use, this is the moment for human beings as a presence [13]. End-of-life care involves personal life experiences which require specific knowledge at a specific moment (kairos), where the interests of the patient and the professional come together. Although treatment and prognosis lie legally with the physician, this is the time for reflection and care, and it is the nurse who is there [14], in his or her sensitivity towards the suffering of another, who is conscious of their own death. It is the nurse who gets closer to the phenomenon, going beyond the superficial and accessing its essence; this is the epistemological value of the nurse's knowledge in end-of-life care.Regarding the appropriateness of actions, at this time nothing is definite. Presence, trust and understanding of the circumstances are factors which enable the nurse to comprehend, to maintain an aid relationship and to give personalized care [15]. In end-of-life care, reality is not a fact separate from experiences, but requires subjectivity to be articulated comprehensively. The whole cannot be isolated in the transition between life and death and for this reason, a hermeneutic explanation of meaning should be provided, one which goes beyond inference derived from a group of hypotheticaldeductive proposals. In the end-of-life care process, when technical recommendations lack the sense to make a rational decision regarding the end and evaluative neutrality is not possible, the guiding interests of nursing knowledge should be studied. Such knowledge includes three types of intra-theoretical interests: technical interest, practical interest and emancipatory interest [16]. The nurse, who becomes close to the phenomenon both as a mortal and professional being, is in an unachievable situation for whatever objectifying knowledge [17]; it is this source of knowledge which only the nurse can access.

\section{References}

1. Gadamer HG (1996) The Enigma of Health: The Art of Healing in a Scientific Age. Stanford University Press, Chicago.

2. Vig EK, Pearlman RA (2004) Good and bad dying from the perspective of terminally ill men. Arch Intern Med 164: 977-981.

3. Nolte K (2008) "Telling the painful truth"-nurses and physicians in the nineteenth century. Nurs Hist Rev 16: 115-134.

4. Bonny B, Henderson A (1996) Nature of decision-making in the terminally ill patient. Cancer Nurs 19: 384-391.

5. Fernández-Sola C, Granero-Molina J, Aguilera Manrique G, Castro-Sánchez AM, Hernández-Padilla JM, et al. (2012) New regulation of the right to a dignified dying in Spain: Repercussions for nursing. Nurs Ethics.

6. Earle V (2010) Phenomenology as research method or substantive metaphysics? An overview of phenomenology's uses in nursing. Nurs Philos 11: 286-296.

7. Glaser BG, Strauss AL (1965) Awareness of Dying, Part 4. Aldine, New York.

8. Chochinov HM (2004) Dignity and the Eye of the Beholder. J Clin Oncol 22: 1336-1340.

9. Calman L (2006) Patients' views of nurses' competence. Nurse Educ Today 26: 719-725.

10. Fernández-Sola C (2012) Facing death in health sciences. Almería University Publications, Almería.

*Corresponding author: José Granero-Molina, Department of Nursing and Physical Therapy, Carretera Sacramento S/N, University of Almeria (04120), Spain, Email: jgranero@ual.es

Received July 02, 2012; Accepted July 04, 2012; Published July 06, 2012

Citation: Granero-Molina J (2012) End-of-Life Care: A Paradigm of Nursing Knowledge. J Nurs Care 1:e113. doi:10.4172/2167-1168.1000e113

Copyright: ( 2012 Granero-Molina J. This is an open-access article distributed under the terms of the Creative Commons Attribution License, which permits unrestricted use, distribution, and reproduction in any medium, provided the original author and source are credited. 
11. Habermas J (2009) On the logic of social science. Tecnos, Madrid.

12. Aristotle (2009) The Nicomachean Ethics. Oxford University Press, Oxford.

13. Fadahunsi A (2003) Philosophy, science and technology. Hope Publishing Company, Carol Stream.

14. Robichaux CM, Clark AP (2006) Practice of expert critical care nurses in situations of prognostic conflict at the end of life. Am J Crit Care 15: 480-489.
15. Bach V, Ploeg J, Black M (2009) Nursing roles in End-of-Life Decision Making in Critical Care Settings. West J Nurs Res 31: 496-512.

16. Habermas J (1995) Knowledge and human interests. Universitat de Valencia, Valencia.

17. Gadamer HG, Weinsheimer J, Marshall DG (2004) Truth and Method. (2ndedn), Continuum International Publishing Group, New York.
Submit your next manuscript and get advantages of OMICS Group submissions

Unique features:

- User friendly/feasible website-translation of your paper to 50 world's leading languages Audio Version of published paper

Digital articles to share and explore

Special features:

- 200 Open Access Journals

15,000 editorial team

- 21 days rapid review process

Quality and quick editorial, review and publication processing

- Indexing at PubMed (partial), Scopus, DOAJ, EBSCO, Index Copernicus and Google Scholar etc

- Sharing Option: Social Networking Enabled

- Authors, Reviewers and Editors rewarded with online Scientific Credits

Better discount for your subsequent articles

Submit your manuscript at: http://www.omicsonline.org/submission/ 